Note

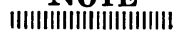

\title{
Application of Reagent Paper to the Preparation of Samples for Beta Activity Measurements
}

\author{
Katsuaki Fukuda, Kazuyuki Sugiyama and Atsushi Mizuike \\ Faculty of Engineering, Nagoya University, Chikusa-ku, Nagoya
}

Received February 26, 1970

\section{Introduction}

Numerous techniques have been proposed for preparing samples for beta activity measurements with an end-window type GeigerMüller counter. However, it is generally very difficult to prepare thin solid samples with an even and reproducible distribution from aqueous solutions containing various inorganic and organic matters as well as beta-emitting nuclides. This paper describes a successful application of a reagent paper (dithizone paper) to beta activity measurements of ${ }^{210} \mathrm{Bi}$ ( $\mathrm{RaE}$ ). Reagent papers, which are prepared by impregnating filter paper with essentially waterinsoluble organic reagents (e.g., dithizone, $p$-dimethylaminobenzylidenerhodanine, etc.), have been developed by the present authors ${ }^{1,2}$ ) (K.F. and A.M.) for the preconcentration of desired elements from matrices in trace element analysis.

\section{Experimental}

\section{$2 \cdot 1$ Apparatus}

A Fujitsu end-window type Geiger-Müller counter (Window $1.5 \mathrm{mg} / \mathrm{cm}^{2}$ thick and $2.7 \mathrm{~cm}$ dia., Scaler SA-250).

\section{$2 \cdot 2$ Reagents}

${ }^{210} \mathrm{Bi}$ solutions $(0.05-10 \mu \mathrm{g} \mathrm{Bi} \text { per } \mathrm{m} l)^{3)}$ : Add RaDEF (The Radiochemical Centre, Nitrates in $2.5 M$ nitric acid, ca. $50 \mu \mathrm{Ci}$ ) and $0.5 \mu \mathrm{g}$ of bismuth carrier to nitric acid to give $0.2 \mathrm{ml}$ of $5 M$ nitric acid solution. Pour this solution onto a $1-\mathrm{cm}$ dia. $\times 3-\mathrm{cm}$ column containing $2.5 \mathrm{~g}$ of strongly basic anion-exchange resin (Amberlite IRA-410, 100-200 mesh, C1-form), pretreated with $5 M$ nitric acid, at a flow rate of 0.5 $\mathrm{m} l / \mathrm{min}$. Pass $8 \mathrm{~m} l$ of $5 M$ nitric acid and 10 $\mathrm{m} l$ of $0.2 M$ nitric acid, successively, through the column at the same rate. Discard the first 10-m $l$ effluent containing $\mathrm{RaD}$ and $\mathrm{RaF}$. Collect the following $8-\mathrm{m} l$ effluent in a $10-\mathrm{m} l$ volumetric flask, add $1 \mathrm{~m} l$ of $0.3 M$ nitric acid containing $0-100 \mu \mathrm{g}$ of bismuth, and dilute to the mark with water.

Buffer solution (pH 5): $\mathrm{Mix} 150 \mathrm{~m} l$ of 0.2 $M$ acetic acid and $350 \mathrm{ml}$ of $0.2 M$ sodium acetate.

All the reagents used were of reagent grade. Water purified by distillation and ion exchange was used throughout the work.

\subsection{Preparation of reagent paper}

Immerse a filter paper (Toyo Roshi No. 7, $2.2 \mathrm{~cm}$ dia.) into ca. $25 \mathrm{ml}$ of $1 \%(\mathrm{w} / \mathrm{v})$ chloroform solution of dithizone for ca. $30 \mathrm{~min}$. Remove the filter paper with polyethylene tweezers, blot off the excess of reagent solution with tissue paper, and allow to air-dry. Immerse the filter paper into $0.1 M$ nitric acid for ca. $5 \mathrm{~min}$, remove it with the tweezers, and allow to air-dry. The reagent paper impregnated with ca. $5 \mathrm{mg}$ of dithizone can be stored for at least 2 months without any deterioration.

\subsection{Procedure}

Place $1 \mathrm{~m} l$ of ${ }^{210} \mathrm{Bi}$ solution in a $50-\mathrm{m} l$ beaker, and add $15 \mathrm{ml}$ of buffer solution. Adjust the $\mathrm{pH}$ to ca. 5 with $0.1 \mathrm{M}$ sodium hydroxide, and dilute to $30 \mathrm{~m} l$ with water. Put a reagent paper between two glass chimneys (Fig. 1), applying a small amount of Cemedine $\mathrm{C}$ (nitrocellulose adhesive) to the edges of the chimneys, and fix with the aid of a polyvinyl chloride adhesive tape. Pour 


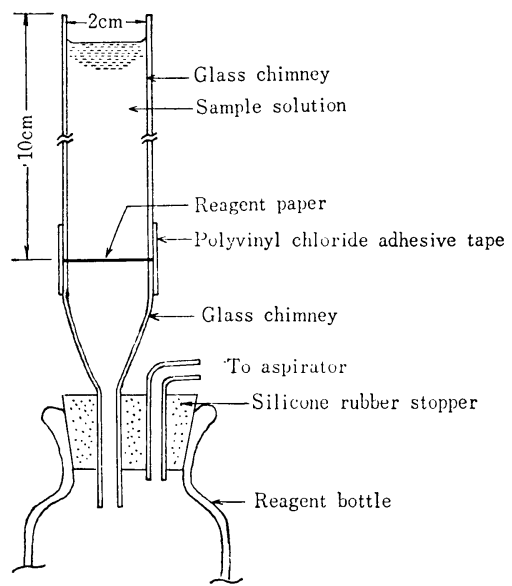

Fig. 1 Filter apparatus.

the solution into the upper chimney, and filter it through the reagent paper at an average flow rate of ca. $8 \mathrm{~m} l / \mathrm{min}$ under suction. Return the filtrate in the reagent bottle to the upper chimney, and repeat the filtration five times. Then wash the reagent paper with a few $\mathrm{m} l$ of water, and dry under an infrared lamp. Remove the reagent paper from the filter apparatus, place in a stainless steel shallow cup ( $2.5 \mathrm{~cm}$ dia., $0.6 \mathrm{~cm}$ high), and measure the beta activity at a sample-to-window distance of ca. $1.8 \mathrm{~cm}$.

\section{Results and Discussion}

Fig. 2 shows the effects of number of filtra-

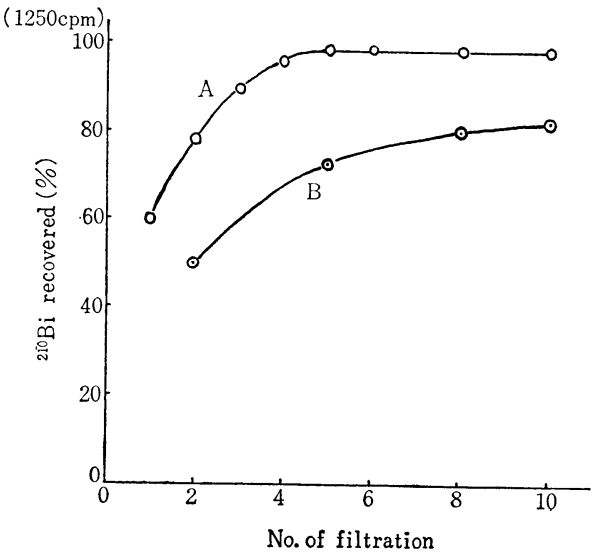

Fig. 2 Effects of number of filtration and flow rate on ${ }^{210} \mathrm{Bi}$ recovery. $\mathrm{Bi} 1 \mu \mathrm{g}$, Solution volume $30 \mathrm{ml}, \mathrm{pH} 5$, Av. flow rate $(\mathrm{A}) \sim 8 \mathrm{ml} / \mathrm{min}$.; (B) $\sim 10$ $\mathrm{ml} / \mathrm{min}$. tion and flow rate on ${ }^{210} \mathrm{Bi}$ recovery. Quintuplicate filtration at an average flow rate of ca. $8 \mathrm{~m} / / \mathrm{min}$ assures $98 \%$ yields in the collection of $1 \mu \mathrm{g}$ of bismuth from a $30-\mathrm{m} l$ solution of $\mathrm{pH}$ 5. The ${ }^{210} \mathrm{Bi}$ recovery is lower at an average flow rate of ca. $10 \mathrm{ml} / \mathrm{min}$. This may be connected with the fact that the solution passes through restricted parts of the reagent paper when the average flow rate exceeds ca. $8 \mathrm{ml} / \mathrm{min}$. In this case, uneven distribution of ${ }^{210} \mathrm{Bi}$ on the reagent paper was found by autoradiography.

The dependence of ${ }^{210} \mathrm{Bi}$ recovery on $\mathrm{pH}$ of the solution was investigated. Curve $\mathrm{A}$ in Fig. 3 shows that the ${ }^{210} \mathrm{Bi}$ recovery is $98 \%$

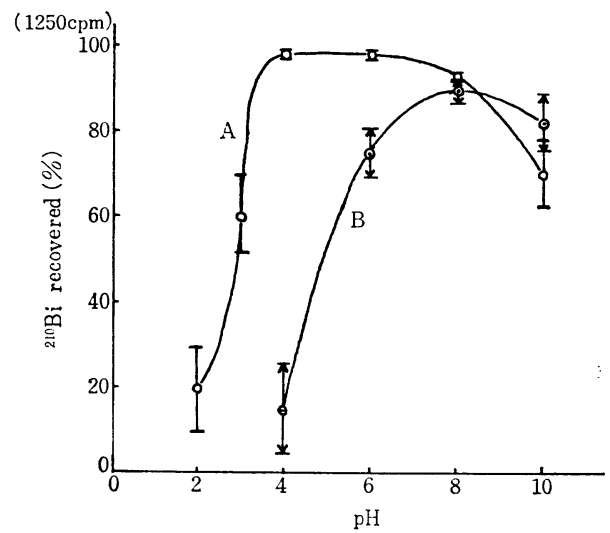

Fig. 3 Effect of $\mathrm{pH}$ on ${ }^{210} \mathrm{Bi}$ recovery. Bi $1 \mu \mathrm{g}$, Solution volume $30 \mathrm{ml}$, No. of filtration 5, Av. flow rate $\sim 8 \mathrm{ml} / \mathrm{min}$, (A) Reagent paper, (B) Filter paper. (Mean and range of 3 measurements are indicated.)

over the $\mathrm{pH}$ range 4-6. Compare this curve with Curve B, which was obtained by the use of filter paper (Toyo Roshi No. 7) instead of reagent paper in the proposed technique.

The effects of bismuth quantity and solution volume on ${ }^{210} \mathrm{Bi}$ recovery are summarized in Table 1.

In order to investigate the distribution of ${ }^{210} \mathrm{Bi}$ on a reagent paper, circular pieces (ca. $0.28 \mathrm{~cm} \mathrm{dia.)} \mathrm{were} \mathrm{cut} \mathrm{out} \mathrm{of} \mathrm{the} \mathrm{reagent} \mathrm{paper}$ with a punch, and the radioactivity of each piece was measured. The results shown in Fig. 4 suggest the homogeneous distribution 
Table 1 Effects of bismuth quantity and solution volume on ${ }^{210} \mathrm{Bi}$ recovery

\begin{tabular}{c|c|c}
\hline $\begin{array}{c}\text { Solution volume } \\
(\mathrm{m} l)\end{array}$ & $\begin{array}{c}\text { Bi present } \\
(\mu \mathrm{g})\end{array}$ & $\begin{array}{c}{ }^{210} \mathrm{Bi} \text { recovered } \\
(\%)\end{array}$ \\
\hline \multirow{3}{*}{30} & 0.05 & 100 \\
& 1 & 98 \\
& 10 & 99 \\
\hline \multirow{2}{*}{90} & 0.05 & 98 \\
& 1 & 97 \\
& 10 & 92 \\
\hline
\end{tabular}

$\mathrm{pH} 5$, No. of filtration $5, \mathrm{Av}$. flow rate $\sim 8 \mathrm{~m} l / \mathrm{min}$.

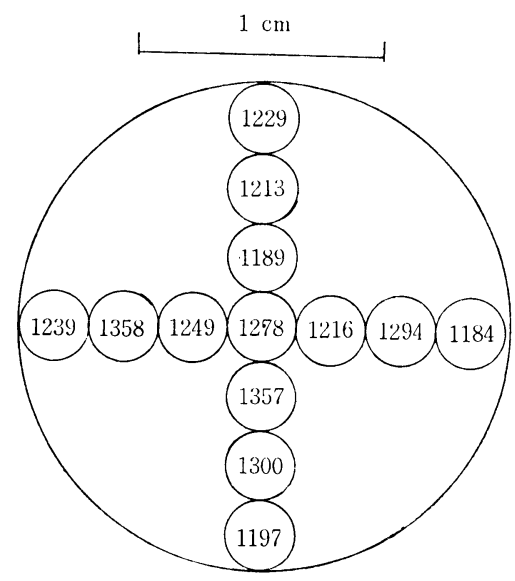

Mean 1254 counts per $10 \mathrm{~min}$ Rel. std. dev. $4.7 \%$

Fig. 4 Localized measurement of ${ }^{210} \mathrm{Bi}$ activity of reagent paper. Counts per $10 \mathrm{~min}$ per piece $(\sim 0.28 \mathrm{~cm}$ dia.).

of ${ }^{210} \mathrm{Bi}$, which is confirmed by an autoradiograph reproduced in Fig. 5.

The reproducibility of the proposed technique was compared with that of the conventional coprecipitation technique. In the latter, a ferric chloride solution containing $2 \mathrm{mg}$ of iron and $2 \mathrm{M}$ ammonium hydroxide were added to a sample solution, and the resulting precipitate was filtered off on a filter paper and airdried. Ten samples were prepared by each technique for beta counting. The results sum-

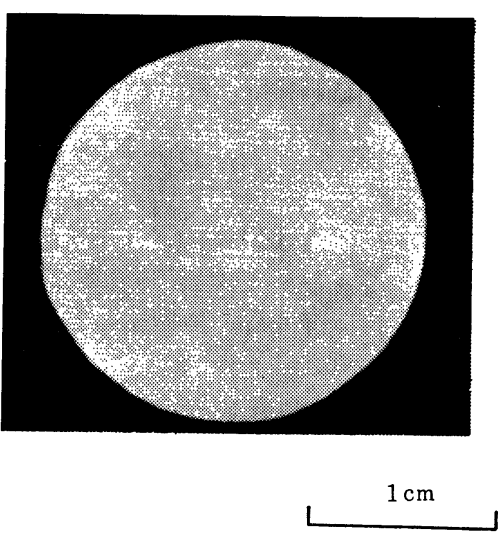

Fig. 5 Autoradiograph showing distribution of ${ }^{210} \mathrm{Bi}$ on reagent paper. Fuji process ranchromatic film. Contact method. Exposure 24-hr. Positive.

marized in Table 2 show the better reproducibility of the proposed technique.

Table 2 Reproducibility test

\begin{tabular}{c|c|c|c}
\hline Technique & $\begin{array}{c}\text { No. of } \\
\text { samples }\end{array}$ & $\begin{array}{c}\text { Mean } \\
\text { (counts } \\
\text { per 5 min) }\end{array}$ & $\begin{array}{c}\text { Rel. std. } \\
\text { dev. } \\
(\%)\end{array}$ \\
\hline Reagent paper & 10 & 6127 & 1.7 \\
\hline Coprecipitation & 10 & 5820 & 3.7 \\
\hline
\end{tabular}

Bi $1 \mu \mathrm{g}$, Solution volume $30 \mathrm{ml}, \mathrm{pH} 5$, No. of filtration 5 , Av. flow rate $\sim 8 \mathrm{ml} / \mathrm{min}$.

The time required for preparing a sample is ca. $40 \mathrm{~min}$. The proposed technique may also be applied to various beta-emitting nuclides by the use of dithizone or other reagent papers.

\section{References}

1) K. Fukuda and A. Mizuike: Japan Analyst, 17, 65 (1968)

2) K. Fukuda and A. Mizuike : ibid., 18, 1130 (1969)

3) F. Nelson and K.A. Kraus: J. Am. Chem. Soc., 76, 5916 (1954) 